\title{
Faking or Convincing: Why Do Some Advertising Campaigns Win Creativity Awards?
}

Raoul V. Kübler, Institute of Innovation Research, Christian-Albrechts-University at Kiel, Germany, E-mail: kuebler@bwl.uni-kiel.de Dennis Proppe, G|PREDICTIVE Gradient GmbH, Hamburg, Germany, E-Mail: dp@gpredictive.de

\begin{abstract}
Since the Sarbanes-Oxley Act was passed in 2002, it has become commonplace in the advertising industry to use creativity-award-show prizes instead of gross income figures to attract new customers. Therefore, achieving a top creativity ranking and winning creativity awards have become high priorities in the advertising industry. Agencies and marketers have always wondered what elements in the advertising creation process would lead to the winning of creativity awards. Although this debate has been dominated by pure speculation about the success of different routines, approaches and strategies in winning creativity awards, for the first time our study delivers an empirical insight into the key drivers of creativity award success. We investigate what strategies and which elements of an advertising campaign are truly likely to lead to winning the maximum number of creativity awards. Using a sample of 108 campaigns, we identify factors that influence campaign success at international advertising award shows. We identify innovativeness and the integration of multiple channels as the key drivers of creativity award success. In contrast to industry beliefs, meaningful or personally connecting approaches do not seem to generate a significant benefit in terms of winning creativity awards. Finally, our data suggest that the use of so-called "fake campaigns" to win more creativity awards does not prove to be effective.
\end{abstract}

JEL-classification: M37, M31, C30

Keywords: advertising agencies, advertising award shows, new business, creative success, fake campaigns, partial least squares

Manuscript received November 22, 2010, accepted by Manfred Schwaiger (Marketing) January 9, 2012.

\section{Introduction and Research Concept}

Being in the top 10 in various agency ranking systems has become high priority for many advertising agencies. This desire is explained primarily by the understanding that major brands and marketers that are looking for new agencies often pre-select their candidates according to the placement of an ad agency in various ranking systems (Butkys and Herpel 1992; Helgesen 1994). This type of preselection is based on an old tradition in the advertising industry and was reported as early as the 1960 s (Ogilvy 1963). Since then, the industry has developed several ranking systems, which judge agencies based on income figures, the overall success of an agency at award shows such as the Cannes Lions or the One Show, or a variety of individual expert evaluations (e.g., Gross Income Rankings, National Creativity Rankings, or subjective agency rankings developed by individual marketing managers of leading brands).

Until 2001, the vast majority of rankings was based on various income figures such as gross income or accumulated media volume of an agency, under the assumption that these figures clearly reflect the competence of an agency. In the wake of the Enron and WorldCom scandals, the US government enacted the so-called Sarbanes-Oxley Act (SOX) in 2002. 
This legislation increased investor protection and, under the threat of a jail sentence (up to 20 years for managers who were found to be responsible), banned companies from publishing incorrect information (Sarbanes-Oxley-Act 2002). With these new regulations in place, major networks were afraid that individual subsidiaries might provoke severe consequences for the parent company if they independently published incorrect or unverified figures. Thus, all agencies in the network were forced to first (or only) report their income figures to their particular parent company and to stop publishing income-related figures, for example, for ranking purposes. Up to that point, most national income rankings had been based on disaggregated and voluntary information on a national subsidiary level. Since 2002, and as a consequence of increasing concerns of the holding companies, income figures became available only on an aggregated level and could no longer be used for national rankings.

Because of the lack of reliable individual income figures for the individual subsidiaries and the national agencies, the industry shifted its focus more toward creativity (Myers 2004). This shift explains why creativity rankings have gained importance in agency pre-selection. Thus, winning creative awards and achieving top results in creative rankings have become the key promotion tools, and the industry today also uses increasing amounts of resources for participation in creativity award shows (Wentz 2005) and strives for top positions in annual national creative rankings (e.g., the Ad Age ranking (Ad-Age-Ranking 2009) in the US or the W\&V/Horizont ranking (W\&V-Kreativ-Ranking 2009) in Germany).

In general, these rankings are based on the annual overall results of an advertising agency in the most prestigious international award shows, such as the Cannes Lions, the Clio Awards, the One Show, the European ADC Awards and a group of various content-specific or national award shows. The rise in importance of winning awards in these shows has led to a shift in agency behavior. As winning creativity awards became a major topic in the industry, agencies started to implement different routines to maximize their number of creativity awards. In addition to making serious financial efforts to attract the industry's top creative people, some agencies even started to compete by offering years of free work to clients, who were known to approve the production of more creative ads, if they switched agencies. These offers clearly underline the importance to advertising agencies of award shows and creative reputation.

Most agencies believe that their clients are less creative or that they restrict the agencies' creative competence by their strategic concerns or risk aversion (El-Murad and West 2003). To showcase their creative skills, some copywriters and art directors started to develop campaigns for "alibi" or fictitious clients. As another strategy, agencies at times try to maximize their outcomes at award shows by submitting advertisements not only for their real clients but also for alibi clients. Producing advertising for fictitious clients allows agencies to avoid daily business restrictions or long discussions with clients or product managers, who may want to replace creative concepts with less creative approaches (West 1993).

In most award shows, submissions must be aired or published only once to qualify, so agencies started to hire pro-bono clients such as bakeries or pet shops to fulfill the minimum show requirements for fictitious campaigns. To be able to submit these socalled fake campaigns, agencies mostly work for free and even pay for the one-time airing fees.

Today, copywriters and graphic artists continue to speculate as to which factors and elements in the process of idea generation and ad planning, conceptualization, design, and execution play decisive roles in winning creativity awards.

Furthermore, the knowledge that agencies try to maximize their success at award shows leads to the question of whether creativity award shows or creative rankings can successfully reflect the abilities and competence of an advertising agency. In other words, what does award-show success portray? Does winning creativity awards indicate real market competence and an ability to combine the individual communication requirements of a client with the creative competence of the agency, or does it only indicate the artistic feeling for great ideas reflected in outstanding but fake campaigns without any business background?

In summary, one can observe that agencies invest significant time and human and capital resources for the sole purpose of winning awards. Given the fact that marketers currently tend to pre-select agencies according to their success at award shows, to the extent that winning creative awards is crucial for commercial success, three important questions arise: 
- First, which factors and strategies in the ad development process result in campaigns and agencies winning creativity awards?

- Second, what exactly does winning creativity awards reflect? In other words, does working creatively guarantee winning creativity show awards?

- Answering the first and the second questions might also simultaneously deliver the answer to a third question: Are creativity rankings the appropriate instrument for marketers to use to preselect agencies?

\section{Research Gap and Contribution}

Creativity research has a long and fruitful tradition in psychology and marketing. Whereas most studies from the marketing side were oriented more toward effectiveness, psychological studies focused more on defining and measuring creativity (Haberland and Dacin 1992). The early field of psychological studies can be divided into three different approaches: The first - and earliest - approach aims at identifying the traits of creative people (Barron 1955; Barron and Harrington 1981; MacKinnon 1987). Creativity in these studies was based mostly on three main characteristics: originality, the adaptiveness to reality and development and elaboration.

The second approach of fundamental psychological studies focused on process-oriented factors, which may influence or enhance creativity or stages of the creative process (Bruner 1962; Newell, Shaw, and Simon 1959). In these studies, the fundamental concept of "novelty" was introduced as a key characteristic of creativity. Finally, the third and smallest area of psychological studies attempted to identify the particular characteristics of creative outcomes (Besemer and O'Quin 1986; Besemer and Treffinger 1981). Following this school of thought, Jackson and Messick (1965) introduced a multi-item approach that identifies four underlying dimensions of creativity: unusualness, appropriateness, transformation and condensation. Finally, Amabile (1983) started a new development in psychological creativity research by focusing on creativity-enhancing factors in terms of working atmosphere (Amabile, Conti, Coon, Lazenby, and Herron 1996) or employee development (Mumford and Simonton 1997).

Although earlier studies relied on various items to measure the specific creativity aspects, the study by Amabile and later studies returned to a simple measurement approach, which asks participants to directly judge overall creativity. Relying on the different results of the three approaches, further psychological studies took a closer look at the different outcomes of creativity. Thereby, the focus lay primarily on the influence of creativity on employee development (Andrews and Smith 1996), better working atmosphere (Amabile, Tighe, Hill and Hennessey 1994), better sales (Moorman and Miner 1997; Song and Montoya-Weiss 2001) and enhanced product or corporate performance (Deshpandé, Farley, and Webster 1993).

In terms of marketing research, creativity is addressed from two perspectives: The first school of thought focuses on the impact of creativity on product development (Sethi, Smith, and Park 2001) and new product performance (Im and Workman 2004; Moorman and Miner 1997). These studies relied heavily on the results from the various psychological studies mentioned above. The second approach to marketing research in terms of creativity focuses more on the impact of creativity on marketing performance and, in particular, on creativity in advertising. This research area can also be divided into two different approaches. Whereas the first group of studies attempted to identify specific factors that may influence or produce the perceived creativity of an advertisement, the other group is oriented more toward output and questions particularly the efficiency of creative advertising. The first group focused mainly on the factors that may help increase advertising creativity (Ang, Lee, and Leong 2007; Kilgour and Koslow 2009; Pieters, Warlop, and Wedel 2002). This focus may lead to a better understanding of how customers perceive advertising creativity (Haberland and Dacin 1992; Michell 1984) and may explain the differences in assessing advertising creativity between agency workers (Nyilasy and Reid 2009) and their clients (Devinney, Dowling, and Collins 2005; Koslow, Sasser, and Riordan 2003) and the creative differences between copywriters and art directors (Young 2000).

Another area of advertising-related creativity research focused on the positive impact of advertising creativity on advertising effectiveness in general (Rossiter 2008) and on sales gains in particular (Bell 1992; Bogart, Tolley, and Orenstein 1970; ElMurad and West 2003; Smith, MacKenzie, Yang, Buchholz, and Darley 2007). In addition to these effectiveness-oriented advertising studies, research also addressed other outcomes of creativity in terms 
of market share gains (Buzzell 1964), differences in long- and short-term impacts of creative advertising (Jones 1995), increased brand recall (Stone, Besser, and Lewis 2000), better brand attention (Pieters, Warlop, and Wedel 2002), greater brand awareness (Gibson 1996), the link between ad likeability and sales performance (Bergkvist and Rossiter 2008), better persuasion rates (Till and Baack 2005) and an enhancement of the perceived brand quality (Dahlén, Rosengren, and Törn 2008). Finally, research explored the positive effects of advertising creativity on brand image and trust enhancements (Li, Dou, Wang, and Zhou 2008).

Like most product development studies, the majority of this communication-oriented research operationalized creativity using items or measurement approaches from basic psychological studies. Although this measurement approach seems to be well established and appropriate for use, other studies on creativity efficiency can be found that operationalize "creative advertising" by defining it as "advertising that won creative awards" (Csikszentmihalyi 1997; El-Murad and West 2003; Kover, Goldberg, and James 1995; Saffert and Reinartz 2011). Although this approach seems to be well accepted, it is surprising that, to the best of our knowledge, no study has yet explored whether this operationalization is correct. Hence, if winning creativity awards is influenced not only by the particular degree of creativity used but also by other - situational or strategic - factors such as personal connections with awardshow juries or the ability to produce fake campaigns of the respective agency, one must be aware that such an operationalization might be biased by these non-observable factors. Therefore, our study will not only identify different factors that will help agencies win creativity awards, but also clarify whether creativity awards can simply be used as an easy, appropriate and, in particular, tested measure for creative advertising.

The contributions of this study are as follows: First, we theoretically derive a novel set of factors that influence the success of an individual campaign in a creativity award show allowing us to find an answer to our first question. Second, we test the influence of several strategic factors and routines on creativityaward-show success. The results reveal which individual factors, elements, and routines in the adcreation process drive the overall creativity-awardshow outcomes and may help us to find answers to our second and third research questions. Our results will show agencies which of these factors should be enforced and which factors can be neglected and will thus help agencies to maximize their awardshow outcome.

In the following section, we develop a conceptual model and identify hypotheses regarding the impact of creative, executional (e.g., the layout, the approach or the choice of the media channels) and organizational factors on award-show performance. We aim to answer the three research questions by using data from 108 campaigns of more than 40 international and highly ranked award shows. In the third section, based on our empirical findings we develop several implications for ad agencies to improve their individual creativity-award-show outcomes and to maximize the individual placement in annual creativity rankings. These implications should help agencies to more effectively attract new business and new clients. At the end of our paper, we provide suggestions for further research.

\section{Conceptual Framework and Hypotheses}

Provided that winning awards and being a leader in creative business rankings is an important reference tool for agencies to promote their competence, academic studies should also focus on the success factors of agencies in these award shows. Our study defines creative success as being successful in creativity award shows. A top position in a creativity ranking can be secured only by winning as many awards as possible. To identify the key drivers of this creative success, we introduce a conceptual model as depicted in Fig. 1.

To develop our research hypotheses toward the question of which elements, factors or routines help win creativity awards, we review a wide range of literature addressing creativity and advertising. Thus, we rely on two different sources of literature and theories. First, hypotheses will be derived from empirically oriented academic literature focusing on factors that influence creativity in general, but not on winning award shows. Second, we also consider more practice-oriented publications such as educational books for copywriters or art directors, which deal in a more detailed way with the topic of advertising and award shows, but may lack solid empirical justification.

To answer to our first research question, i.e., whether creativity is actually a key driver for success in creativity award shows, we first examine the psycho- 
logical understanding of creativity. According to this understanding, creativity in general consists of three key elements (Im and Workman 2004): newness or novelty (Amabile 1983; Amabile 1988; Amabile 1993), meaningfulness (Goldenberg, Mazursky, and Solomon 1999), and connectedness or originality (Sternberg and Lubart 1999).

In terms of advertising, novelty can be defined as a fundamental breaking away from existing schemes or routines (Ang, Lee, and Leong 2007; Ang and Low 2000). This process leads to a significant change or adaptation in the cognitive structure of the viewer and will help to enhance the attentive process and the memory effect. Earlier studies showed that a creative ad has to use innovative, fresh, unique, different and new ways to break from pre-existing schema and to deploy a sense of the unexpected (Bogart, Tolley, and Orenstein 1970; Haberland and Dacin 1992). These findings are supported by the empirical results of Ang and Low (2000), who found evidence for a positive correlation between the degree of innovation and the overall creative appearance of an ad. According to the most prominent textbooks for copywriters or art directors, newness or innovativeness in creative advertising can be expressed by the degree of layout innovation, the innovativeness of the overall approach of a campaign, or at least by the innovativeness of media usage (Aitchison 1999; Sullivan 2003).

Thus, it can be assumed that the use of novel ideas, new layouts, and innovative concepts plays an important role in creative success and will lead to more creative awards (Ang and Low 2000; Blasko and Mokwa 1986). Summarizing the aspects of novelty in the ad-creation process leads to our first hypothesis:

H1: Campaigns that use a more novel or innovative approach are more successful in creativity award shows than campaigns that do not use such an approach.

Previous research noted that novelty alone might not be sufficient to define creativity (Ang, Lee, and Leong 2007; Baack, Wilson, and Till 2008; Haberland and Dacin 1992). Andrews and Smith (1996), therefore, introduced the additional concept of meaningfulness. This aspect of creativity is defined as the extent to which an idea deviates in a meaningful way from ordinary praxis. In terms of advertising creativity, meaningfulness can be understood as the link between an idea and the relevance of this idea to its audience (Lee and Mason 1999). In addition, Goldenberg, Mazursky, and Solomon (1999) emphasized that random advertising creativity without any relevance may be harmful at worst and inefficient at best. These assumptions were also made in the study by Smith, MacKenzie, Yang, Buchholz, and Darley (2007). Advertising creativity might thus be understood as the combination of relevance and divergence. In terms of advertising creation, this definition implies that the ad not only has to rely on a novel communication approach (that is divergent from existing forms of communication), but the message also has to convey productrelated information relevant to the customer. This means that the overall idea, the message, and the information about the advertised product must convey a singular message that is relevant to the targeted customer (Ang, Lee, and Leong 2007; Baack, Wilson, and Till 2008; Smith, MacKenzie, Yang, Buchholz, and Darley 2007).

Later research on advertising creativity defined meaningfulness as the central idea or theme of an advertisement (Thorndyke 1977). Meaningfulness can therefore be defined as the relevant key benefits on which the specific product is positioned in the marketplace (Haberland and Dacin 1992). In other words, meaningfulness is secured when the key message of an ad can rely on the clear, appropriate and non-replaceable benefits (Runco and Charles 1993) of the advertised product. Therefore, advertisements for products with these non-replaceable benefits perform better in creativity award shows because they can create original, unique, and new campaign approaches that will secure meaningfulness. The practice-oriented advertising literature confirms this effect (Aitchinson 1999; Sullivan 2003). Thus, we hypothesize the following:

H2: Campaigns that use a more meaningful approach for the creative implementation of an idea are more successful at winning creativity awards than campaigns that do not rely on such an approach.

The third and final criterion for defining advertising creativity is connectedness (Amabile, Conti, Coon, Lazenby, and Herron 1996; Ang, Lee, and Leong 2007; Im and Workman 2004). In terms of advertising creativity, connectedness can be understood 
as the ability of an advertisement to build an enduring link or a lasting connection between the viewer and the promoted product or brand (Dahlén, Rosengren, and Törn 2008). Previous research showed that such a connection can be best realized when a particular ad causes an emotional or rational resonance (Lubart 2001) in the consumer. This resonance should enforce the connection between the viewer and the advertisement's message or at least the advertised product (Sasser and Koslow 2008).

Previous research showed that this resonance can be best obtained when the creative idea is linked to a product specific and unique benefit that satisfies a certain need (Sternberg and Lubart 1999). Thus, information perceived as inappropriate or useless does not build a positive connection with its viewer and vice versa. These findings are in line with the suggestions of Keil (1975), who claimed that a creative advertisement should always follow a main strategy of connecting the product to a certain benefit. Again, the practice-oriented advertising literature confirmed this effect. That is, both, leading textbooks and agency guidelines for copywriters suggest that the search for a creative idea should always be based on the benefit of the respective product because only this individual benefit will lead to an enduring connection to the advertisement's audience (Aitchison 1999; Sullivan 2003).

In summary, it can be assumed that if an advertisement is to win creative awards, it will have to connect to its audience by communicating a meaningful product benefit using a novel communication approach. This leads to our third hypothesis:

H3: Campaigns that use a more connective approach as operationalized by the communication of a certain product benefit will perform better in creativity award shows than campaigns that do not rely on such an approach.

Although simply working creatively when designing an ad should result in better creativity awards performance, the authors suspect that agencies also use several other instruments and strategies to enhance their creativity-award-show outcomes. This assumption is underlined by the findings of Amabile (1997), who noted that people easily learn to adapt their creative behavior to reward systems. When rewarded, people stop trying to identify new and innovative ways to generate creative approaches or creative ideas and begin to rely on the rewarded and successful approach they have already developed. In the case of advertising creativity, this phenomenon indicates that creativity in award shows is bound to a small number of different creative patterns and is influenced by specifically developed strategies.

Transferring these assumptions to agencies, one must be aware that the industry has managed to establish several reward systems for winning creativity awards. Agencies, for example, reward their employees with bonuses for winning creative awards. In addition, in most agencies, the professional advancement of copywriters or art designers is closely related to their success in award shows.

As a consequence, one must assume that these different incentives and rewards programs will lead to the development of specific strategies to maximize the individual award-show outcomes. In the following section, we develop additional hypotheses concerning these additional variables, strategies and instruments.

In the last decade, integrated thinking has become an important issue in advertising (Kotler and Keller 2006; Naik and Raman 2003). Most clients today challenge their agencies to create ideas not for only one communication channel but for all possible channels. Thus, creative people are forced to find the "one" idea that works for all channels. In multi-channel campaigns, the main creative idea has to be as flexible as possible if it is to succeed and needs to be adapted to all communication channels; we can thus assume that these multi-channel ideas will be judged as more creative (Aitchison 1999). Therefore, we believe that work from multi-channel campaigns tends to fare better in creativity award shows (creative performance or award-show performance) than other campaigns (Johnson 2003). This trend is also reflected by the official calls of festival juries for an emphasis on more integrated campaigns. Thus, the authors assume the following:

H4: Advertisements designed for a multi-channel campaign are more successful at creativity award shows than are advertisements designed for a single-channel campaign.

Although creativity is understood as a key element in attracting new clients, most agencies fear that their creative ability in daily business is restricted by the clients' strategy or the clients' overall creative competence, which is generally assumed to be lower 
than that of the agencies. In addition, several academic studies noted a serious divergence in the perception of creativity between agencies and their clients (El-Murad and West 2003; Helgesen 1994, Koslow, Sasser, and Riordan 2006; White 2003). These authors asked leading creative directors to explain the old industry belief and any discrepancy with the truth. They found that many marketers seem to fear that too much creativity may not be sufficiently product-oriented and will therefore be either misinterpreted or misunderstood by the customer. West, Kover, and Caruana (2008) arrived at similar findings in their study. Previous research showed that, in some cases, marketers even tend to interpret higher forms of creativity as a type of risk taking (El-Murad and West 2003). As a result, they are afraid that too much creativity might even hurt future sales or market share (Li, Dou, Wang, and Zhou 2008). In addition, clients are often believed by their own agencies to be more reluctant to take risks and to be less creative than the workforce of the agency (Kover, Goldberg, and James 1995). This phenomenon results in the belief that marketers may not have the ability to identify the potential of a creative campaign or concept (Devinney, Dowling, and Collins 2005; Kover 1995).

Although marketers find creative agencies by preselecting them according to their rank, they are nevertheless said to be overburdened by the cuttingedge concepts of some copywriters. This dilemma puts agencies in a difficult situation: On the one hand, they need awards to attract new clients, but on the other hand current clients will likely not allow the agency, or only rarely, to work on a creative level that is sufficient to win further awards. As a result of this difficult situation, agencies sometimes stopped trying to convince their conservative clients to accept more creative or otherwise outstanding campaigns and rather started to produce cuttingedge concepts on their own without clients. To maximize their potential number of awards and to have the opportunity to showcase their unbounded creative potential, some agencies are even said to have complete campaigns, or at least some strong concepts, in reserve. The agencies then seek alibi clients that fit these concepts or campaigns. For the opportunity to submit these ideas to award shows, the agencies are sometimes willing to work for free and even to pay media fees. In general, typical pro-bono or "fictitious" clients for these concepts are small or local shops, such as bakeries or pet shops (Kore- mans 2007). Online Appendix A shows some typical fake campaigns developed by leading international agencies such as BBDO or DDB for small German bakeries and local charitable societies.

Because these campaigns are not restricted by the client's strategy objections, the cognitive creative potential of the marketer's management, or market and media restrictions, it can be hypothesized that fake campaigns allow a higher level of creativity than ordinary campaigns. Therefore, we postulate the following:

H5: Campaigns created solely for creativity award shows ("fake campaigns") perform better in creative advertising award shows than ordinary campaigns created for real clients.

In addition to the above mentioned strategies in the ad-development process, agencies can use other strategies to maximize their creativityaward-show outcomes: Design, layout and conceptual elements can influence the number of creativity awards for a single ad as well as situational factors such as workplace atmosphere, routines or management techniques used by the designing ad agencies.

Numerous empirical studies focused on the influence of factors such as atmosphere, motivation, and leadership style on creativity (Amabile 1998; Amabile, Conti, Coon, Lazenby, and Herron 1996; Amabile, Tighe, Hill, and Hennessey 1994; Blasko and Mokwa 1986; El-Murad and West 2004; Koslow, Sasser, and Riordan 2003; Kover, James, and Sonner 1997; Ruscio, Whitney, and Amabile 1997).

As mentioned above, some agencies have begun to acquire special clients as well as special "creative" individuals who are well known for creativity-award-show success and outstanding creativity. The larger networks such as DDB, Jung von Matt and BBDO even started to integrate special departments into their networks to accommodate these experts. The only objective of these "creative task forces" is to create award-winning campaigns and to maximize the number of creativity awards won by the agencies. Because of cost effects, we also expect large and experienced companies to offer more attractive workplaces and more sophisticated management techniques (Aitchison 1999). Furthermore, because of pathway effects (Barney 1991; Barney 2001), we expect older agencies to have established more crea- 
tive routines than younger ones. Moreover, experienced industry managers with a strong reputation have suggested that a link between the age of an agency and its contacts with jury members in award shows might exist because these jury members are primarily recruited from experienced agencies or from associations such as the national Art Directors Club. Knowing jury members and their special preferences might also increase the overall performance of an advertisement in creativity award shows. Therefore, we integrate these ideas into the following three hypotheses:

H6: Campaigns created by larger (a) and more experienced (b) agencies that have more contact with associations (c) are more successful in winning creativity awards than campaigns from smaller (a) and less experienced (b) agencies that have less contact with associations (c).

In addition to the mentioned direct effects of the different variables on creativity-award-show performance, we consider several indirect effects of these different variables. Below, we incorporate these indirect effects into the structural equation model.

As mentioned, the so-called fake campaigns are created solely for creativity award shows. By doing so, agencies attempt to demonstrate their creative skills without being restrained by real clients' wishes, briefings, or strategies. Therefore, it could be assumed that these campaigns will be based on stronger creative approaches than other campaigns. If this assumption is true, it must also be assumed that all factors that define creativity in general will also have an indirect impact on these fake campaigns. Therefore, we incorporate indirect effects from the variables "novelty," "meaningfulness" and "connectedness" in a "fake campaign" in the model. This leads to the following hypotheses:

H7: Fake campaigns use more novel (a), more meaningful (b), and more connecting (c) approaches than other campaigns submitted to creativity award shows.

We also mentioned above that typical "fake campaigns" are aired only once in local media to fulfill the minimum submission criterion of creativity award shows. Given this and the fact that these special advertisements are based on a single concept, it must also be assumed that there is a negative indirect association between the variable "multi-channel approach" and the variable "fake campaign." This leads to our eighth hypothesis:

H8: Fake campaigns are less likely to be multichannel campaigns than other campaigns submitted to creativity award shows.

In addition, older agencies will have developed better routines to maximize their creativity-awardshow outcomes. One reason for this trend is that more experienced agencies might have more resources to perform this extra work. Another reason might be that more experienced agencies with more connections to the award-show industry and their respective associations will also know how to place good "fake campaigns" without being blamed for doing so. We account for this advantage of older agencies by including further indirect effects from the variables "agency age," "agency size" and "association members" in the variable "fake campaign." Additionally and as a consequence of pathway effects, we assume that older agencies will be larger and will have more contacts with creative associations. We account for these effects by incorporating indirect effects from the variable "agency age" in the variables "agency size" and "association members." This leads to our ninth hypothesis:

H9: The use of fake campaigns is positively influenced by the age (a), size (b), and number of contacts with associations (c) of the agency.

In addition to fake campaign-related effects, we address agencies' capability to produce multichannel campaigns. Thus, we assume that agency size may also have a positive influence on the ability of an agency to work on multi-channel campaigns. This assumption may be justified primarily by the fact that small agencies tend to specialize themselves for individual channels such as online marketing or below-the-line marketing, whereas larger agencies and network agencies try to gather all the aspects of marketing under one roof. We incorporate this assumption by an indirect effect from the variable "agency size" on the variable "multichannel approach." Thus, we derive our final hypothesis:

H10: The use of a multi-channel approach is positively influenced by the size of an agency.

On the basis of this conceptual framework (see Fig. 1), we test our hypotheses (see Tab. 1 for a summary) to address the question of which of these factors drive the overall creativity-award-show outcomes of an agency. 


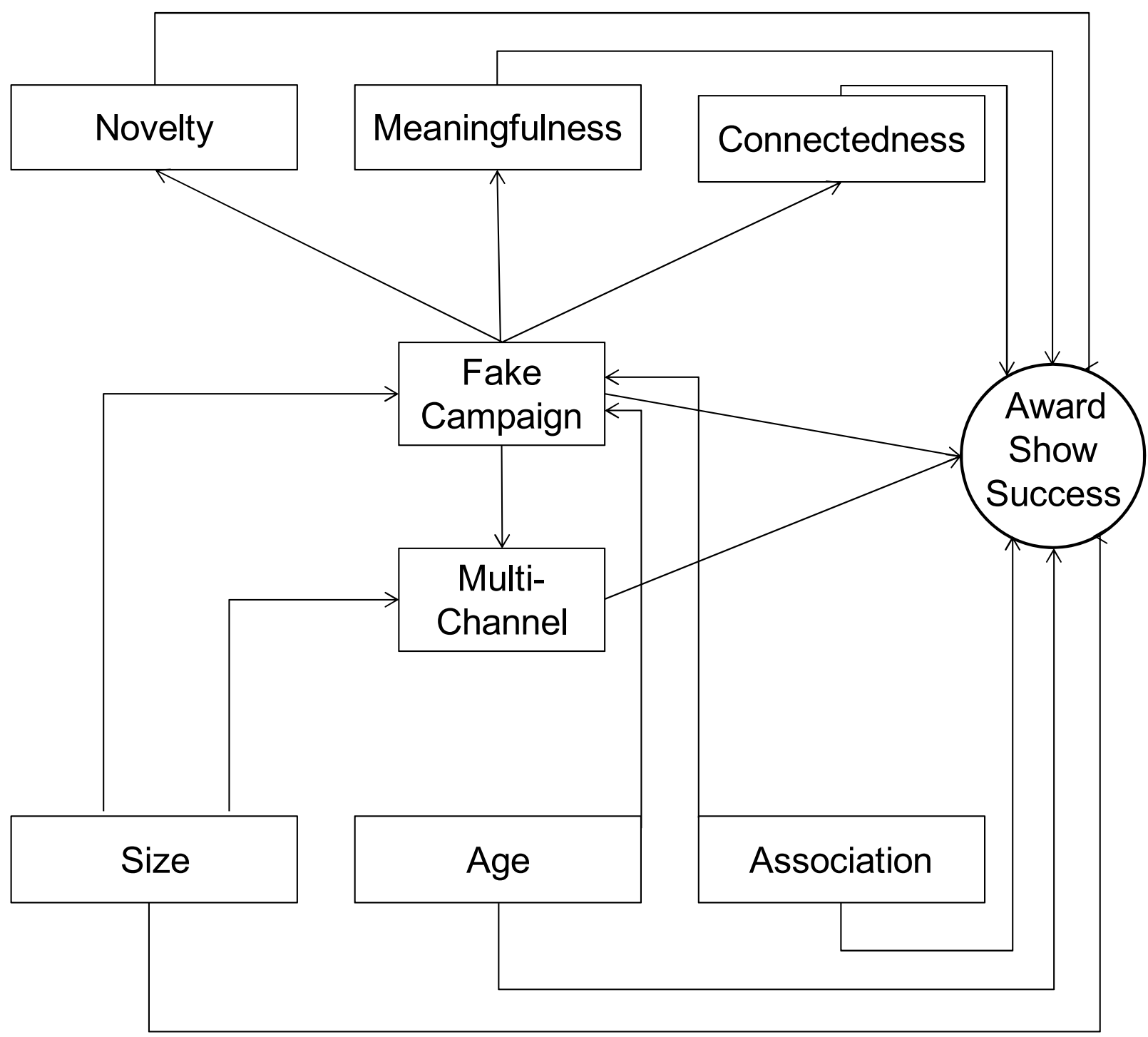

\section{Empirical Analysis}

To empirically test our conceptual model, we collected data from 108 German campaigns from a total of 40 creativity award shows in 2006. Data collection was mainly divided into two parts: factual data gained by intense investigation and the results of an expert questionnaire that evaluated several campaign features. In the following section, we describe in detail our data sample and followed by a description of our expert survey and measurement development. The section closes with specifications and explanations of our estimation process and a description of our empirical results.

\subsection{Sample}

All campaigns in the sample were at least shortlisted in one of the 40 considered award shows. The award shows were chosen based on their importance for the national German creativity ranking. The award-show sample considered only rankings acknowledged by the German Art Directors Club - the most important advertising 


\section{Table 1: Summary of the Hypotheses}

\begin{tabular}{|c|c|}
\hline $\mathrm{H}_{\mathrm{x}}$ & Hypothesis formulation \\
\hline H1 & $\begin{array}{l}\text { Campaigns that use a more novel or innovative approach are more successful in creativity award shows than are campaigns } \\
\text { that do not use such an approach. }\end{array}$ \\
\hline $\mathrm{H} 2$ & $\begin{array}{l}\text { Campaigns that use a more meaningful approach to the creative implementation of an idea are more successful in winning } \\
\text { creativity award than are campaigns that do not rely on such an approach. }\end{array}$ \\
\hline $\mathrm{H}_{3}$ & $\begin{array}{l}\text { Campaigns that use a more connective approach by communicating a product benefit will perform better in creativity award } \\
\text { shows than will campaigns that do not rely on such an approach. }\end{array}$ \\
\hline $\mathrm{H}_{4}$ & $\begin{array}{l}\text { Advertisements designed for a multi-channel campaign are more successful at creativity award shows than are advertise- } \\
\text { ments designed for a single-channel campaign. }\end{array}$ \\
\hline $\mathrm{H}_{5}$ & $\begin{array}{l}\text { Campaigns created solely for creativity award shows ("fake campaigns" or "gold ideas") perform better in creative advertis- } \\
\text { ing award shows than do ordinary campaigns created for real clients. }\end{array}$ \\
\hline $\mathrm{H} 6_{\mathrm{a}-\mathrm{c}}$ & $\begin{array}{l}\text { Campaigns created by larger (a) and more experienced (b) agencies that have more contacts with associations (c) are more } \\
\text { successful in winning creativity award than are campaigns from smaller (a) and less experienced (b) agencies that have less } \\
\text { contact with associations (c). }\end{array}$ \\
\hline $\mathrm{H}_{7 \mathrm{a}-\mathrm{c}}$ & $\begin{array}{l}\text { Fake campaigns use more novel (a), more meaningful (b), and more connecting (c) approaches than other campaigns sub- } \\
\text { mitted to creativity award shows. }\end{array}$ \\
\hline H8 & $\begin{array}{l}\text { Fake campaigns are less likely to be multi-channel campaigns than other campaigns that are submitted to creativity award } \\
\text { shows. }\end{array}$ \\
\hline $\mathrm{H}_{9 \mathrm{a}-\mathrm{c}}$ & $\begin{array}{l}\text { The use of fake campaigns is positively influenced by the age (a), size (b), and number of contacts with associations (c) of the } \\
\text { agency. }\end{array}$ \\
\hline $\mathrm{H}$ & ulti-channel \\
\hline
\end{tabular}

association in Germany - as a base for the national agency ranking. This approach promises unique data with high internal validity because juries in all award shows are said to rely on identical criteria when judging submissions. These data were collected from online sources and with the help of the German Art Directors Club. All 108 campaigns in the sample can be watched and listened to in online Appendix B (Print/Ambient/ Internet/BtL) and online Appendix C (Video/Cinema/Radio). Both appendices also show the creative performance of the individual advertisements and a separate fake index indicating the number of experts who judged the advertisement as a fake campaign. The sample consists mainly of print and outdoor advertisements, followed by the categories TV/cinema and radio (see Figure 2). Campaigns were submitted by 27 German advertising agencies ranging in size from 25 to 1,400 employees (see Table 2).

\subsection{Expert Survey}

To gather data regarding some of the campaignspecific features (e.g., innovativeness, whether fake or not and use of USP), the authors developed a web questionnaire and presented it to experts from the advertising industry (for further details, see online Appendices D and E). To reduce possible bias, we used a panel of five experts, who rated each campaign in the sample. This approach has the advantage that the judgments do not rely on the potentially subjective ratings of any single expert. All experts are highly reputed in the advertising industry and were either leading creative directors or leading managers of advertising agencies. In addition, all experts were members of a festival or an award-show jury in the five years prior to our inquiry, thus ensuring that all experts had an insight into how juries select winners. None of these experts was or is on the jury of any of the award shows in the sample, which guarantees some degree of neutrality. The intercoder reliability (ICR) of the five different expert lies at .876 , which can be considered as acceptable. We calculated the ICR according to the well-established approach of McGraw and Wong (1996) using the ICC procedure in SPSS. To ensure comparability with other studies we thereby only relied on the experts' evaluations and did not include their stated confidence. Including this measure would lead to an even higher ICR measure. 
Table 2: Sample statistics

\begin{tabular}{lc} 
Item & Percentage \\
\hline Agency size & \\
\hline $1-49$ employees & $18.5 \%$ \\
\hline $50-99$ employees & $37.0 \%$ \\
\hline $100-499$ employees & $33.3 \%$ \\
\hline $500-999$ employees & $7.0 \%$ \\
\hline 1, ooo-1,600 employees & $3.5 \%$ \\
\hline Agency type & \\
\hline Owner-managed agency & $59.3 \%$ \\
\hline Network-based agency & $40.7 \%$ \\
\hline Association members & \\
\hline o & $25.9 \%$ \\
\hline 1 & $7.0 \%$ \\
\hline 2 & $11.1 \%$ \\
\hline 3 & $11.1 \%$ \\
\hline 4 & $11.1 \%$ \\
\hline 5 & $18.5 \%$ \\
\hline 6 & $7.0 \%$ \\
\hline 7 & \\
\hline & \\
\hline & \\
\hline
\end{tabular}

\section{Product type}

\begin{tabular}{lc}
\hline Durable & $38.9 \%$ \\
\hline FMCG & $26.8 \%$ \\
\hline Consumer good & $34.3 \%$ \\
\hline Client type & \\
\hline B2B & $11.1 \%$ \\
\hline B2C & $75.0 \%$ \\
\hline Charitable & $13.9 \%$ \\
\hline
\end{tabular}

Note: $N_{\text {agencies }}=27$ and $N_{\text {campaigns }}=108$

We aggregated these individual ratings by their "confidence-based weighted mean" (Van Bruggen, Lilien, and Kacker 2002). This measure accounts for the confidence that experts have in their specific ratings. The expert can thereby express his or her confidence in the judgments by choosing a level between one and five. The higher the confidence level, the higher the weight the respective expert receives in the subsequent score calculation. Van Bruggen, Lilien, and Kacker (2002) delivered empirical evidence that this technique leads to improved judgments and better aggregation.

\section{Figure 2: Distribution of Media Types Used for Campaigns}

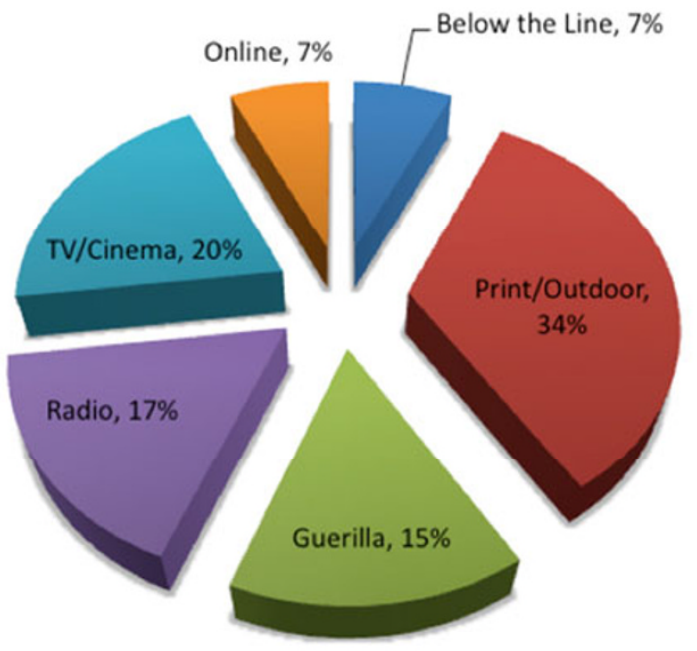

The next section describes the operationalization of the variables according to the research hypotheses and the collection of the variable information. Because a large portion of the constructs from the hypotheses are not directly observable, we use latent variable operationalizations for them.

\subsection{Measure Development}

Following the standard procedures for scale development (Rossiter 2002), we based our scales on a review of academic literature, advertising textbooks and interviews with senior creatives (e.g., copywriters, art directors, and creative directors) from several leading German advertising agencies. Because we wanted to account for as many perspectives and methods of the executional and conceptual aspects of ad creation as possible, we were not able to rely completely on existing scales and, therefore, had to identify and use new items that would properly measure the intricacies of the ad-creation process.

We measure the performance of an ad quite straightforwardly as the overall "creativity-awardshow outcome" of the individual advertisement in all 40 award shows. The data were gathered by 
intense offline and online searches in the individual award-show databases. The majority of award shows are based on a similar ranking system. Individual placements range from a "Grand Prix" (the highest possible rating) resulting in five points, to a shortlist nomination (the lowest possible rating) resulting in one point. Thus, we could simply summarize the individual outcome of a campaign in a creativity award show. Because some awards are very well known and have numerous applicants, we weighted the individual awards according to the official weights of the German Creativity Ranking supplied by the German Art Directors Club.

Data concerning the construct "novelty" of an ad campaign (hypothesis 1) were gathered through expert judgments. Because each expert had to rate all 108 campaigns, we tried to keep the questionnaire as short as possible. Previous research showed that creatives and especially advertisers have a skeptical view of research and science (Chong 2006; Kover 1996). Those studies state that creatives believe that research is not definable and that creativity is a more intuitive process that cannot be separated into different aspects or parts. Moreover, some creatives even believe that research constrains their own creativity. Thus, the authors tried to avoid any turning-away behavior or rejection by using wellknown and straightforward measures from the practice, which were easy for our experts to understand. Following some industry textbooks and previous research, all experts were asked to directly rate the degree of novelty of a campaign with respect to (1) media use, (2) graphic design and (3) content approach (Aitchison 1999; Sasser, Koslow, and Riordan 2007; Sullivan 2003). All items were measured on a five-point Likert scale.

To measure the second construct, "meaningfulness" (hypothesis 2), we also used three different items based on expert judgments. As shown earlier, "meaningfulness" stands in close relationship to the relevance of the advertisement's message to consumers. To measure this relevance, we relied on three different items derived from the well-known Resource-Based View (RBV) and the concept of the Unique Selling Proposition (USP). According to Barney (1991), each of the following criteria has to be fulfilled to create a relevant and unique resource. First, the message of the campaign has to focus on an aspect of a product that is (1) unique in supply. In addition, this aspect has to be (2) non-imitable and
(3) non-substitutable. All five experts were asked to separately rate each advertisement based on these three criteria. Expert judgments were based on a five-point Likert scale from 1 (no agreement) to 5 (high agreement).

As shown during the development of the hypothesis, an advertisement should build a lasting connection between the viewer and the advertised product or brand. To ensure such a connection, the message conveyed has to evoke a rational or emotional resonance in the viewer. Previous research showed that such a resonance can be evoked by presenting the viewer with a lasting and relevant product or brand benefit that connects the viewer with the advertisement (Im and Workman 2004) and leads to an enduring memory of the ad or the advertised product. Following the need for easy-to-understand items and a short questionnaire, we operationalize our construct "connectedness" - in accordance with the findings of Bergkvist and Rossiter (2007) - with a single item that measures the connecting benefit. We asked our experts straightforwardly if a campaign communicates some sort of connecting benefit for the advertised product. Experts could rate the individual appearance of a communicated connecting benefit on a five-point Likert scale from 1 (no agreement) to 5 (high agreement).

The information for hypothesis 4 regarding whether a campaign's main idea followed a multi-channel approach was measured by a dummy variable that took the value of $o$ when the concept was created for one channel alone and that took the value of 1 when the idea was integrated into more than one channel. Again, single-item measurement is in accordance with the findings of Bergkvist and Rossiter (2007). Data were gathered from a search of special ad databases and the web presences of the agencies.

The independent variable "fake campaign" measures whether a campaign was created exclusively for creativity award shows ("fake campaign") (hypothesis 5), as determined by subjective judgment (yes/no) from our five experts.

Finally, the influence of the agency-related variables (hypotheses 6a, 6b, and 6c) is measured in accordance with Bergkvist and Rossiter (2007) by an individual item for the variables "age of the company in years," the "number of employees" to control for the size, and the "number of Art Directors Club members in the organization" for the variable "creative association." The Art Directors Club is a German association of successful professionals from the 
Table 3: Variable Measurement and Data Collection

\begin{tabular}{|c|c|c|c|}
\hline Variable & Operationalization & Data collection & $\mathbf{H}_{\mathbf{x}}$ \\
\hline Novelty & 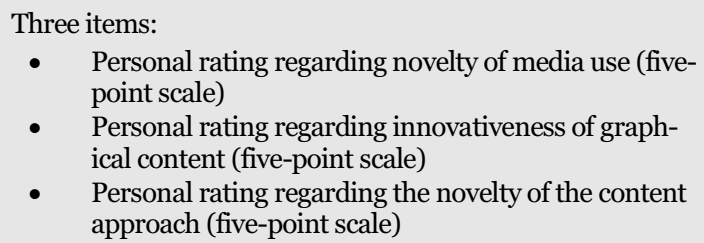 & Expert judgment & $\begin{array}{l}\mathrm{H}_{1} \\
\mathrm{H}_{7}\end{array}$ \\
\hline Meaningfulness & $\begin{array}{l}\text { Three items: } \\
\text { - Personal rating regarding the uniqueness of the } \\
\text { communicated key product aspect (five-point Likert } \\
\text { scale) } \\
\text { - Personal rating regarding the imitability of the } \\
\text { communicated key product aspect (five-point Likert } \\
\text { scale) } \\
\text { - Personal rating regarding the substitutability of the } \\
\text { communicated key product aspect (five-point Likert } \\
\text { scale) }\end{array}$ & Expert judgment & $\begin{array}{l}\mathrm{H}_{2} \\
\mathrm{H}_{7}\end{array}$ \\
\hline Connectedness & $\begin{array}{l}\text { Personal rating regarding the utility generated by the } \\
\text { communicated key benefit (five-point Likert scale) }\end{array}$ & Expert judgment & $\begin{array}{l}\mathrm{H}_{3} \\
\mathrm{H}_{7}\end{array}$ \\
\hline $\begin{array}{l}\text { Multi-Channel } \\
\text { Campaigns }\end{array}$ & $\begin{array}{l}\text { Dummy variable indicating whether the campaign's main } \\
\text { idea is used in multiple channels }(1 / 0)\end{array}$ & $\begin{array}{l}\text { Web search in online databases and in } \\
\text { the web presence of the creating agency }\end{array}$ & $\begin{array}{l}\mathrm{H}_{4} \\
\mathrm{H}_{9}\end{array}$ \\
\hline Fake Campaign & $\begin{array}{l}\text { Expert judgment regarding whether the campaign is fake } \\
(1 / 0) \text {. }\end{array}$ & Expert judgment & $\begin{array}{l}\mathrm{H}_{5} \\
\mathrm{H}_{9}\end{array}$ \\
\hline Age & Single item: Age of the agency (years) & $\begin{array}{l}\text { Web search in online databases and in } \\
\text { the web presence of the creating agency }\end{array}$ & $\begin{array}{l}\mathrm{H}_{62} \\
\mathrm{H}_{9}\end{array}$ \\
\hline Size & Single item: Number of employees & $\begin{array}{l}\text { Web search in online databases and in } \\
\text { the web presence of the creating agency }\end{array}$ & $\begin{array}{l}\mathrm{H}_{6} \\
\mathrm{H}_{9}\end{array}$ \\
\hline $\begin{array}{l}\text { Association Mem- } \\
\text { bership }\end{array}$ & Single item: Number of ADC members & $\begin{array}{l}\text { Web search in online databases and in } \\
\text { the web presence of the creating agency }\end{array}$ & $\begin{array}{l}\mathrm{H}_{6 c} \\
\mathrm{H}_{9}\end{array}$ \\
\hline
\end{tabular}

media industry. Thus, membership is a good indicator of (past) creative achievements of that person and the network this person may be connected with in the industry. These variables were collected using online sources such as company websites or other industry or association websites; the individual variables and their operationalizations are summarized in Table 3.

\subsection{Specification and Estimation}

Given the latent nature of most of the variables, the use of reflective and formative constructs and the causal structure of our research hypotheses, we use the partial least squares (PLS) approach for estimating the data (Chin 1998; Chin and Todd 1995). This approach is advocated for path models with latent variables that are observed by multiple indicators (Fornell and Bookstein 1982; Fornell and Cha 1994). In addition, PLS allows for moderate sample sizes in contrast with the classic OLS estimation
(Fornell and Cha 1994). Thus, the PLS approach seems well suited for this study. The structural model derived from the hypotheses is shown in Figure 1. We estimated our model using the software application SmartPLS (Ringle, Wende, and Will 2005). The results are displayed in Table 5 .

\subsection{Results}

Our model explains nearly $24 \%$ of the variance for creativity-award-show success, which can be considered to be substantive. Furthermore, our model delivers a corrected $\mathrm{R}^{2}$ of .146 for multi-channel campaigns, which we also consider to be satisfactory. According to Chin (1998), this is a reasonable fit for a PLS model. Additionally, we validated the estimation by testing the predictive validity with an estimation sample of 80 cases (approximately $75 \%$ of the sample) and a holdout sample of 28 cases (approximately $25 \%$ of the sample). Thereby, we followed Chin and Todd (1995), who proposed that 
an average correlation between predicted and real values in the holdout sample higher than .3 and .5 , respectively, can be considered to be satisfactory. Following Haitovsky (1969), we predicted a holdout sample with all parameters that had a t-value of at least one. With a correlation value of $r=.513$, the prediction satisfies all quality criteria and can be considered good.

To ensure that the measures used for the two reflective constructs are reliable, we calculated their composite reliabilities, Cronbach's alpha and the average variance extracted (AVE). Table 4 provides an overview of all three measures for both constructs. We find all measures to be highly satisfactory. The individual composite reliability values are all higher than 0.8 , which complies with the suggestions made by Churchill (1979). In accordance with the guidelines provided by Nunnally and Bernstein (1994), both Cronbach's alpha values remain higher or near 0.7. At .584 (meaningfulness) and .674 (novelty), the AVE values for both reflective constructs are significantly higher than 0.5 and therefore fulfill the quality criteria mentioned by Fornell and Larcker (1981).

\section{Table 4: Quality Criteria of the Reflective Constructs}

\begin{tabular}{llll} 
& AVE & $\begin{array}{l}\text { Composite } \\
\text { Reliability }\end{array}$ & $\begin{array}{l}\text { Cronbach's } \\
\text { Alpha }\end{array}$ \\
\hline $\begin{array}{l}\text { Meaning- } \\
\text { fulness }\end{array}$ & 0.584 & 0.805 & 0.700 \\
\hline Novelty & 0.674 & 0.861 & 0.756 \\
\hline
\end{tabular}

Our results are mixed, and to some extent, we face surprising and counterintuitive observations. All estimation results are reported in Table 5 .

The assumed positive influence of "novelty" (pc: $.239 ; \mathrm{t}=1.961$ ) on creativity-award-show success as postulated in hypothesis 1 is confirmed. Although novelty seems to be a key driver for winning creativity awards, one has to be aware that path coefficients for "meaningfulness" (pc: -.023; $\mathrm{t}=.230$ ) and "connectedness" (pc: .054; $t=.578$ ) remain insignificant. These findings are counterintuitive to our initial assumptions and surprising, as connectedness and meaningfulness are believed to be basic key components of the understanding of creativity. Our results show that award-show success is explained by presenting something that is simply nov- el rather than novel, meaningful and connecting. Thus, award-show creativity has to be considered as different from the general academic understanding of creativity that postulates the holistic combination of all three characteristics. Therefore, hypotheses 2 and 3 must be rejected.

In contrast to the classic definition of creativity, our results suggest that a campaign that aims only at winning creativity awards has to find novel ways of communication or layout techniques, whereas relying on a relevant or meaningful and connecting message does not seem to be necessary. Although our finding - that working creatively does not automatically lead to winning creativity awards - contradicts conventional wisdom from the advertising industry, it supports the criticism of many marketers that creativity award shows have nothing in common with real, creative, persuading and effective advertising.

Hypothesis 4 postulates a positive effect from multichannel campaigns on creativity-award-show success. With a path coefficient (pc) of .259 and a tvalue of 2.484, the hypothesis is confirmed.

Hypothesis 5 states that campaigns created solely for creativity award shows win more creativity awards on average because their creative approach is not restricted by the client. Contrary to our assumption, the data identify a negative (pc: -.211) and significant $(t=2.775)$ direct effect of the construct "fake campaign" on creativity-award-show success. This finding is quite surprising because the vast majority of creatives, practitioners and critics of creativity award shows have frequently and vigorously asserted the opposite. We assume that this effect is explained primarily by the effect that juries easily identify these "fake campaigns" because of their extensive industry experience. In addition, it can be assumed that the same juries try to protect their shows from external criticism by punishing these obvious fakes. Although this negative direct effect implies that faking dos not seem to pay off, one has to be aware that a fake campaign may pose a better opportunity to show new and more creative approaches in terms of novelty, meaningfulness and connectedness. To account for this phenomenon, the authors calculate the particular net effect for the construct fake campaign by applying formula (1) to the data set.

$$
\begin{aligned}
\text { NFake }= & \text { FaNov*novelty }+ \text { FaMea*meaningfulness } \\
& + \text { FaConn } * \text { connectedness }+ \text { Fake }
\end{aligned}
$$


Table 5: Estimation Results

Standard Error Path Coefficient T Statistics

\begin{tabular}{|c|c|c|c|c|}
\hline Agency Size -> Creativity Award Show Performance & .090 & .002 & .024 & ns \\
\hline Agency Size -> Fake Campaign & .090 & .128 & 1.382 & ns \\
\hline Agency Size -> Multi-Channel & .068 & -.280 & 4.106 & $* * *$ \\
\hline Agency Age -> Creativity Award Show Performance & .076 & -.128 & 1.508 & ns \\
\hline Agency Age -> Fake Campaign & .107 & .125 & 1.089 & ns \\
\hline Association Members -> Creativity Award Show Performance & .103 & -.056 & .523 & ns \\
\hline Association Members -> Fake Campaign & .097 & .170 & 1.740 & * \\
\hline Fake Campaign -> Creativity Award Show Performance & .076 & -.211 & 2.775 & $* * *$ \\
\hline Multi-Channel -> Creativity Award Show Performance & .099 & .259 & 2.484 & $* * *$ \\
\hline Multi-Channel Approach -> Fake Campaign & .078 & -.289 & 3.868 & $* * *$ \\
\hline Meaningfulness -> Creativity Award Show Performance & .095 & -.023 & .230 & ns \\
\hline Fake Campaign -> Meaningfulness & .108 & .231 & 1.973 & * \\
\hline Novelty -> Creativity Award Show Performance & .112 & .239 & 1.961 & * \\
\hline Fake Campaign -> Novelty & .137 & .193 & 1.493 & ns \\
\hline Connectedness -> Creativity Award Show Performance & .088 & .054 & 0.578 & ns \\
\hline Fake Campaign -> Connectedness & .087 & -.134 & 1.417 & ns \\
\hline
\end{tabular}

ns not significant; ${ }^{* *}=$ significant at least at the .95 level; ${ }^{* * *}=$ significant at least at the .99 level

In the equation, NFake is the net effect in terms of extra creativity for a fake campaign. FaNov, FaMea and FaConn are the mean differences in novelty, meaningfulness and connectedness, respectively, between a fake campaign and an ordinary campaign that is submitted to a creativity award show. Fake, novelty, meaningfulness and connectedness represent the direct effects of the particular constructs on creativity-award-show success. It should be kept in mind that most fake campaigns are produced for small alibi clients such as bakeries, pet shops or social initiatives. In exchange for free work, these clients also give their agencies a free hand in terms of the creative execution of their ads. Thus, any additional degree of novelty in the case of a fake campaign can be explained primarily by the absence of business restrictions, prejudices or risk aversion regarding creative ideas on the part of the alibi client. One also has to remember that the direct effect of faking proved to be negative. Therefore, if faking is effective in terms of winning creativity awards, the extra amount of possible creativity (viz. in novelty, meaningfulness and connectedness) will have to outperform the direct negative effect. To obtain the individual mean differences (in this case, equal to the particular unstandardized regression coefficients), we executed three different OLS regressions using the individual latent variable scores of the three latent constructs as dependent variables and the latent variable scores of the latent construct "fake campaign" as an independent variable. The obtained mean differences are reported in Table 6.

To calculate the direct effects from the four latent variables, we followed Reinartz, Krafft, and Hoyer (2004) and used the latent variable scores of the four constructs "fake campaign", “connectedness", "meaningfulness" and "novelty" as independent variables in an OLS regression and the latent variable scores of the construct "creativity-award-show success" as a dependent variable. Table 6 presents an overview of the individual results for all of the variables and the result of the net effect. Because NFake is negative, hypothesis 5 finally has to be rejected. Neither the direct effect of a fake campaign 
Table 6: Net effect calculation of fake campaign

\begin{tabular}{|c|c|c|c|}
\hline Constructs & Mean Difference & Direct Effect & Gains per Fake Campaign (mean differences * direct effects) \\
\hline Novelty & .210 & 20.609 & 4.328 \\
\hline Meaningfulness & .190 & -3.971 & -.755 \\
\hline Connectedness & -.172 & 4.202 & -.723 \\
\hline \multicolumn{4}{|l|}{ Net effect } \\
\hline Fake Campaign & & $-27 \cdot 350$ & -24.500 \\
\hline
\end{tabular}

nor the extra amount of novelty, meaningfulness or connectedness helps these types of campaign to win creativity awards.

Hypotheses $6 \mathrm{a}$ through $6 \mathrm{c}$ postulate various relationships between agency-related factors and winning creativity awards. In all three cases, the path coefficients remain insignificant, with agency age taking a t-value of 1.508 (pc: -.128), agency size taking a t-value of .024 (pc: .002) and association membership taking a $\mathrm{t}$-value of .523 and a path coefficient of -.056. Hence, hypothesis 6 has to be rejected. This finding is also surprising because it contradicts some old industry myths that claim that having good networking skills and experience in various associations is the primary reason for winning creativity awards. Although this finding contradicts our assumptions, it offers an important and valuable insight into the advertising world and refutes an old controversial notion.

Hypothesis 7 consists of three different assumptions and postulates that fake campaigns may use more novel, more meaningful and more connecting approaches. Our empirical findings are mixed. Although the effects for novelty (pc: .193; $\mathrm{t}=$ 1.493) and connectedness (pc: $-.134 ; \mathrm{t}=1.417$ ) remain insignificant, our data reveal a positive and significant influence on fake campaigns of meaningfulness (pc: .231; $\mathrm{t}=1.973$ ). Thus, it seems that fake campaigns are better able to communicate relevant product attributes than their "real" counterparts.

Furthermore, as we had assumed, our results reveal a negative (pc: -.289) and significant ( $\mathrm{t}=$ 3.868) connection between fake campaigns and multi-channel campaigns. This result clearly gives empirical proof to the industry's definition of fake campaigns as typically singular products for small clients that are aired only once in inexpensive media channels that lack a large audience simply to fulfill the submission criteria of the various creativity award shows. Thus, hypothesis 8 can be fully supported.

Hypothesis 9 consists of three different assumptions about fake campaigns. In the case of two of the assumptions, our results do not validate our hypothesis. Thus, the path coefficients for the impact from agency size (pc: .128; $t=1.382$ ) and agency age (pc: .125; $t=1.089$ ) on fake campaign remain insignificant. However, our model finds proof for a significant relationship between association membership and fake campaigns (pc: $.170 ; t=1.740$ ). Thus, our results deliver an indication that agencies with better connections with associations and therefore also with award-show juries more often attempt to maximize their creativity-award-show outcomes with faked campaigns. Again, this finding gives proof to some enduring industry myths and justifies complaints of the numerous critics of the existing awardshow business. Finally, Figure 3 presents an overview of the particular effects.

\section{Discussion}

Although some of our results are surprising, our data deliver important answers to the various research questions raised at the beginning of this paper: First, our results suggest that one does not have to rely on an idea that simultaneously combines novelty, meaningfulness and connectedness to win creativity awards. In fact, winning these awards is more likely to reflect an agency's ability to produce novel approaches in terms of layout generation, conceptualization and media usage. Whereas novelty appears to be a key driver for creativity-awardshow success, meaningfulness and connectedness 
play only a tangential role. This finding is quite appealing because most advertising practitioners - in line with academia -would claim that the most important elements of a successful campaign are a good idea, excellent art direction and a rich dash of creativity. Furthermore, our results acknowledge some old myths and criticisms by many marketers. Because meaningfulness and connectedness do not seem to be relevant to creativity-award-show success, winning these awards does not necessarily imply that an agency is able to create convincing campaigns, which rely on the well-investigated key benefits of products. Creativity award shows, however, seem to focus more on artistic elements than on hard but important strategy issues such as the relevance of the information or the highlighting of a clear product benefit. Therefore, marketers who pre-select agencies based on their creativity-awardshow success or any creativity ranking data should keep this in mind.

Figure 3: Estimation Results of the Conceptual Model

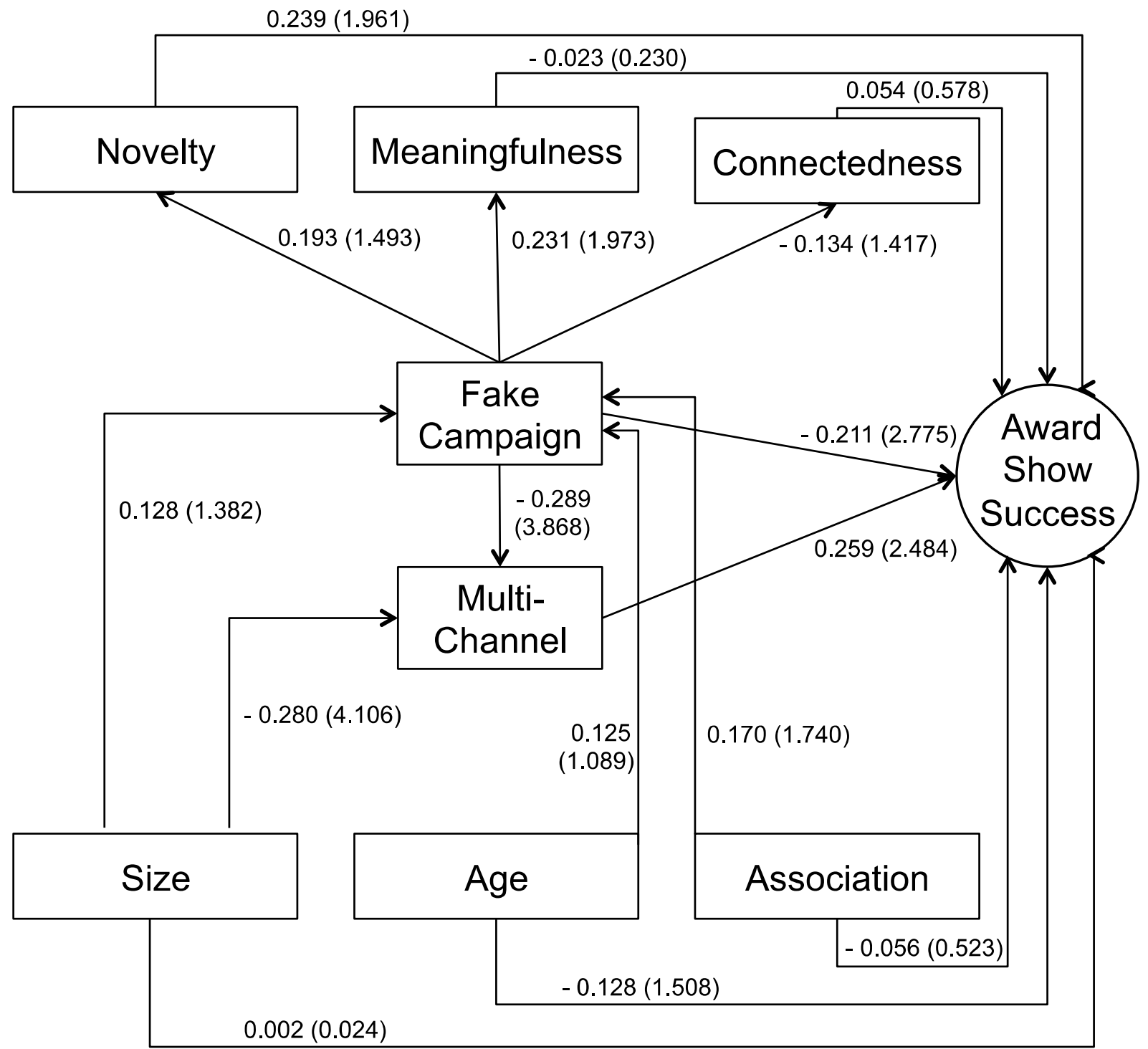


In addition to these market-oriented insights, our results suggest some interesting topics for future research into advertising creativity. Until now, empirical studies have simply operationalized advertising creativity by the fact that these campaigns have won some type of creativity award in various international award shows. Our results suggest that this definition may not be sufficient. Researchers should keep in mind that winning creativity awards primarily reflects the novelty of an approach, whereas the other two aspects of the construct of creativity, i.e., meaningfulness and connectiveness, seem to be ignored by festival juries.

In additional, our study delivers some important answers to our second research question. Our results give further insight into the business of creativity award shows and indicate the significant key drivers of awards success. First, using a multichannel approach appears to be superior in the eyes of the award-show jurors. This finding is understandable because it is harder to create a campaign that works well in different channels (e.g., radio advertisements vs. print ads), and mastering this difficult task seems to be rewarded in the competition.

Second, agencies should stop producing so-called fake campaigns because they do not pay off. Rather, our results indicate that a negative effect exists for "fake campaigns" on creativity-award-show success. We suspect that one main reason behind this counterintuitive effect might be that as pure "award campaigns" are easily identified by the jurors, they might be "punished" by the jury. This phenomenon seems plausible because virtually all creativity award-show juries have an interest in avoiding contributions that were clearly created specifically for the award show. Most creativity awards are heavily discussed in public and in the industry's major magazines. Thus, awarding campaigns that are easily identified as "fake" could result in some loss of reputation of the individual award show. As a consequence, juries may be reluctant to reward campaigns that were created specifically for the award show rather than to attract real customers. Surprisingly, most agencies still try to maximize their performance in creativity award shows by using fake campaigns, even though they should know better because, in several international award shows, the leading creative officers of an agency are also jury members. This trend is impressively underlined by the large number of fake campaigns detected in our sample, in which 32 campaigns were rated as fake by at least 4 of 5 experts.

Our study hereby offers an important insight for both agencies and marketers in the ad generation process. First, the myth and criticism by marketers that winning creativity awards can be explained primarily by good faking abilities and good contacts with the individual award-show juries can be falsified by the empirical results of our study. Second, our results recommend that agencies instead look for novel approaches to ad design and media use. To produce only outstanding but easy-to-identify fake ideas for fictitious and non-paying clients is not sufficient.

Finally, our study provides valuable insight for marketers and answers our third research question: creativity rankings do not necessarily reflect the creative abilities of an ad agency. Marketers should keep this in mind when pre-selecting their agencies. In other words, these rankings do not provide information about an advertising agency's ability to identify and profitably communicate the relevant benefits of a product. However, the rankings offer insight into the capability of the creative workforce to identify novel ways to communicate.

\section{Conclusions and Implications}

Given the results of our study, we can point out important novel insights into the business of advertising award shows: First, our results challenge anecdotal industry knowledge in that we do not find any support for the assertion that fake work is more likely to win creativity awards. Considering that agencies consume many resources in terms of manpower and money for airing time or entrance fees in preparing fake campaigns, we recommend that their spending on these types of projects should be carefully scrutinized because of the unclear effects they have on the overall creative image of the company. Furthermore, the time used to produce real campaigns and to convince marketers is normally paid by the client. Thus, it seems advisable for agencies to switch resources from agency-paid fake projects to client-paid projects, which can be submitted to more than one award show.

The time and resources saved should be invested in creating multi-channel campaigns with innovative and groundbreaking layouts and approaches. Our results show that a suitable and promising concept that will win creativity awards can be identified by 
its ability to be effective not only in one media channel but in all possible channels. Knowing this fact may give the creative workforce or the agencies' consultants a good control measure to identify promising campaign approaches. Thus, they can determine whether an approach or a concept is promising and whether the project should be carried forward or cancelled.

Another industry myth about advertisement submissions in creativity award shows is that they rarely have anything in common with real-life advertising and market restrictions. This wisdom could be partly underlined by the results of this study. We could not identify a positive link between the emphasis on a meaningful product benefit - which effectively connects the ad to its audience - and winning awards. Clients might question the benefit of hiring an agency that wins creative awards with fake ads because, in the broad majority of cases, it must be assumed that clients will prefer agencies that are able to deliver creative solutions within the (often tight) range of the client's guidance.

Apart from these recommendations, we follow the anecdotal industry knowledge that was confirmed by our study. Thus, we recommend the submission of multi-channel campaigns that have an innovative appeal, especially in terms of the design and the overall creative approach. Of course, this practice is easily said but often difficult to do. We suspect that the massive amount of resources devoted to attracting the best creative people in the industry might truly be justified because creative innovation is the factor that separates excellent campaigns from merely good ones. Thus, an advertising agency that aims to earn creative awards should do everything it can to attract creative people and to build an ideafriendly work atmosphere. When hiring new copywriters, art directors, and creative directors to maximize their chances to win creativity awards, agencies should seek experienced creative professionals from older and larger agencies. Potential hires should have worked intensively on multi-channel campaigns and be able to adapt a single idea to all possible channels of advertising. Moreover, these abilities should be focused on more than the membership in famous and prestigious creativity associations because copywriters and art directors from these established associations tend to rely more on fake campaigns rather than on convincing real clients to believe in their concepts.
Furthermore, we would like to encourage the research community to conduct more studies on the link between creativity and the effectiveness of advertising campaigns. At the moment, it does not seem worthwhile for creative professionals to tailor campaigns to an advertised product. If more evidence were available regarding the influence of content fit on ad effectiveness, award-show jurors might take this into consideration. Doing so would eventually lead to more creativity awards for campaigns that offer more than just a "crazy idea," namely, a very good idea that fits the advertised product.

\section{Web-Appendix A:}

Example Fake Campaigns

\section{Web-Appendix B:}

Print BtL Internet Ambient Advertisements

Web-Appendix C:

List of Cinema_TV_Radio Advertisements

Web-Appendix D:

Questionnaire for Print Advertising

\section{Web-Appendix E:}

Questionnaire for Print

\section{Acknowledgements}

We wish to thank Manfred Schwaiger as guest editor and the two anonymous reviewers for their thoughtful comments and suggestions, which significantly helped to improve the quality of this paper. Furthermore, we want to thank Sönke Albers for his valuable comments on previous versions of this manuscript.

\section{References}

Aitchison, Jim (1999): Cutting Edge Advertising: How to Create the World's Best for Brands in the 21st Century, Prentice Hall: Singapore.

Amabile, Teresa M. (1983): The Social Psychology of Creativity: A Componential Conceptualization, Journal of Personality and Social Psychology, 45 (2): 357-376.

Amabile, Teresa M. (1988): A Model Of Creativity And Innovation In Organizations, Research in Organizational Behavior, 10: 123169.

Amabile, Teresa M. (1993): What Does a Theory of Creativity Require?, Psychological Inquiry, 4 (3): 179-181. 
Amabile, Teresa M. (1997): Motivating Creativity in Organizations: On Doing What You Love and Loving What You Do, California Management Review, 40 (1): 39-58.

Amabile, Teresa M. (1998): How to Kill Creativity, Harvard Business Review, 76 (5): 76-86.

Amabile, Teresa M., Regina Conti, Heather Coon, Jeffrey Lazenby, and Michael Herron (1996): Assesing the Work Enviroment for Creativity, Academy of Management Journal, 39 (5): 1154-1184.

Amabile, Teresa M., Elizabeth M. Tighe, Karl G. Hill, and Beth A. Hennessey (1994): The Work Preference Inventory: Assessing Intrinsic and Extrinsic Motivational Orientations, Journal of Personality \& Social Psychology, 66 (5): 950-967.

Andrews, Jonlee and Daniel C. Smith (1996): In Search of the Marketing Imagination: Factors Affecting the Creativity of Marketing Programs for Mature Products, Journal of Marketing Research, 33 (2): 174-187.

Ang, Swee Hoon, Yih Hwai Lee, and Siew Meng Leong (2007): The Ad Creativity Cube: Conceptualization and Initial Validation, Journal of the Academy of Marketing Science, 35 (2): 220-232.

Ang, Swee Hoon and Sharon Y.M Low (2000): Exploring the Dimensions of Ad Creativity, Psychology \& Marketing, 17 (10): 835-854.

Baack, Daniel W., Rick T. Wilson, and Brian D. Till (2008): Creativity and Memory Effects, Journal of Advertising, 37 (4): 85-94.

Barney, Jay (1991): Firm Resources and Sustained Competitive Advantage, Journal of Management, 17 (1): 99-120.

Barney, Jay (2001): Is the Resource-Based 'View' a Useful Perspective for Strategic Management Research? Yes, Academy of Management Review, 26 (1): 41-56.

Barron, Frank (1955): The Disposition toward Originality, Journal of Abnormal Psychology, 51 (3): 478-485.

Barron, Frank and David M. Harrington (1981): Creativity, Intelligence, and Personality, Annual Review of Psychology, 32 (1): $439-476$

Bell, Jack A. (1992): Creativity, TV Commercial Popularity, and Advertising Expenditures, International Journal of Advertising, 11 (2): $165-183$

Bergkvist, Lars and John R. Rossiter (2007): The Predictive Validity of Multiple-Item Versus Single-Item Measures of the Same Constructs, Journal of Marketing Research, 44 (2): 175184.

Bergkvist, Lars and John R. Rossiter (2008): The Role of Ad Likability in Predicting an AD's Campaign Performance, Journal of Advertising, 37 (2): 85-97.

Besemer, Susan and Karen O'Quin (1986): Analyzing Creative Products: Refinement and Test of a Judging Instrument, Journal of Creative Behavior, 20 (2): 115-126.

Besemer, Susan and Donald Treffinger (1981): Analysis of Creative Products: Review and Synthesis, Journal of Creative Behavior, 15 (3): 158-178.

Blasko, Vincent, J. and Michael P. Mokwa (1986): Creativity in Advertising: A Janusian Perspective, Journal of Advertising, 15 (4): 43-50+72.

Bogart, Leo, B. Stuart Tolley, and Frank Orenstein (1970): What One Little Ad Can Do, Journal of Advertising Research, 10 (4): 313.
Bruner, Jerome (1962): The Conditions of Creativity, in: Howard E. Gruber, Glenn Terrell and Michael Wertheimer (eds.): Contemporary Approaches to Creative Thinking, Atherton Press: New York, 1-30.

Butkys, Adolph S. and George Herpel (1992): How Advertising Agencies Handle Their Own Advertising Strategy: An IndustryWide Overview of its Self-Promotion Efforts, Journal of Advertising Research, 32 (5): 18-22.

Buzzell, Robert D. (1964): Predicting Short-Term Changes in Market Share as a Function of Advertising Strategy, Journal of Marketing Research, 1 (3): 27-31.

Chin, Wynne (1998): The Partial Least Squares Approach to Structural Equation Modeling, in: George A. Marcoulides (ed.) Modern Methods for Business Research, Erlbaum: Mahwah, NJ et al., 295-336.

Chin, Wynne and Peter A. Todd (1995): On the Use, Usefulness, and Ease of Use of Structural Equation Modeling in MIS Research: A Note of Caution, MIS Quarterly, 19 (2): 237-246.

Chong, Mark (2006): How Do Advertising Creative Directors Perceive Research?, International Journal of Advertising, 25 (3): 361-380.

Churchill, Gilbert A. (1979): A Paradigm for Developing Better Measures of Marketing Constructs, Journal of Marketing Research, 16 (1): 64-73.

Csikszentmihalyi, Mihaly (1997): Creativity: Flow and the Psychology of Discovery and Invention, Harper Collins: New York.

Dahlén, Micael, Sara Rosengren, and Fredrik Törn (2008): Advertising Creativity Matters, Journal of Advertising Research, 48 (3): 392-403.

Deshpandé, Rohit, John U. Farley, and Frederick E. Webster (1993): Corporate Culture, Customer Orientation, and Innovativeness in Japanese Firms: A Quadrad Analysis, Journal of Marketing, 57 (1): 23-37.

Devinney, Timothy, Grahame Dowling, and Michael Collins (2005): Client and Agency Mental Models in Evaluating Advertising, International Journal of Advertising, 24 (1): 35-50.

El-Murad, Jaafar and Douglas C. West (2003): Risk and Creativity in Advertising, Journal of Marketing Management, 19 (5/6): 657-673.

El-Murad, Jaafar and Douglas C. West (2004): The definition and measurement of creativity: What do we know?, Journal of Advertising Research, 44 (2): 188-201.

Fornell, Claes and Fred L. Bookstein (1982): Two Structural Equation Models: LISREL and PLS Applied to Consumer ExitVoice Theory, Journal of Marketing Research, 19 (4): 440-452.

Fornell, Claes and Jaesung Cha (1994): Partial Least Squares, in: Richard P. Bagozzi (ed.): Advanced Methods of Marketing Research, Blackwell: Cambridge, MA et al., 52-78.

Fornell, Claes and David F. Larcker (1981): Evaluating Structural Equation Models with Unobservable Variables and Measurement Error, Journal of Marketing Research, 18 (1): 39-50.

Gibson, Lawrence D. (1996): What Can One TV Exposure Do? Journal of Advertising Research, 36 (2): 9-18.

Goldenberg, Jacob, David Mazursky, and Sorin Solomon (1999): Creative Sparks, Science, 285 (5433): 1495-1496. 
Haberland, Gabriele S. and Peter A. Dacin (1992): The Development of a Measure to Assess Viewers' Judgments of the Creativity of an Advertisement, Advances in Consumer Research, 19 (1): 817-825.

Haitovsky, Yoel (1969): A Note on Maximization of R2, American Statistician, 23 (1): 20-21.

Helgesen, Thorolf (1994): Advertising Awards and Advertising Agency Performance Criteria, Journal of Advertising Research, 34 (4): 43-53.

Im, Subin and John P. Workman (2004): Market Orientation, Creativity, and New Product Performance in High-Technology Firms, Journal of Marketing, 68 (2): 114-132.

Jackson, Philip, W. and Samuel Messick (1965): The Person, the Product, and the Response: Conceptual Problems in the Assessment of Creativity, Journal of Personality, 33 (3): 309-329.

Johnson, Michael (2003): All Together Now, Design Week, 18 (48): 14-15

Jones, John Philip (1995): Single-Source Research Begins to Fulfill its Promise, Journal of Advertising Research, 35 (3): 9-16.

Keil, John M. (1975): Can You Become a Creative Judge?, Journal of Advertising, 4 (1): 29-31.

Kilgour, Mark and Scott Koslow (2009): Why and How do Creative Thinking Techniques Work? Trading Off Originality and Appropriateness to Make More Creative Advertising, Journal of the Academy of Marketing Science, 37 (3): 298-309.

Koslow, Scott, Sheila L. Sasser, and Edward A. Riordan (2003): What Is Creative to Whom and Why? Perceptions in Advertising Agencies, Journal of Advertising Research, 43 (1): 96-110.

Koslow, Scott, Sheila L. Sasser, and Edward A. Riordan (2006): Do Marketers get the Advertising They Need or the Advertising They Deserve?, Journal of Advertising, 35 (3): 81-101.

Kotler, Philip and Kevin Keller (2006): Marketing Management, Prentice Hall: Upper Saddle River, NY.

Kover, Arthur J. (1995): Copywriters' Implicit Theories of Communication: An Exploration, Journal of Consumer Research, 21 (4): 596-611.

Kover, Arthur J. (1996): Why Copywriters Don't Like Advertising Research - and What Kind of Research Might They Accept, Journal of Advertising Research, 36 (2): 8-11.

Kover, Arthur J., Stephen Goldberg, and William James (1995): Creativity vs. Effectiveness? An Integrating Classification for Advertising, Journal of Advertising Research, 35 (6): 29-40.

Kover, Arthur J., William James, and Brenda S. Sonner (1997): To Whom Do Advertising Creatives Write? An Inferential Answer, Journal of Advertising Research, 37 (1): 41-53.

Lee, Yih Hwai and Charlotte Mason (1999): Responses to Information Incongruency in Advertising: The Role of Expectancy, Relevancy, and Humor, Journal of Consumer Research, 26 (2): 156-169.

Li, Hairong, Wenyu Dou, Guangping Wang, and Nan Zhou (2008): The Effect of Agency Creativity on Campaign Outcomes: The Moderating Role of Market Conditions, Journal of Advertising, 37 (4): 109-120.

Lubart, Todd (2001): Models of the Creative Process: Past, Present and Future, Creativity Research Journal, 13 (3/4): 295308.
MacKinnon, Donald W. (1987): Some Critical Issues for Future Research in Creativity, in: Scott G. Isaksen (ed.): Frontiers of Creativity Research: Beyond the Basics, Bearly: Buffalo, NY, 120130.

McGraw, Kenneth O. and S. P. Wong (1996): Forming Inferences About Some Intraclass Correlation Coefficients, Psychological Methods, 1 (1): 30-46.

Michell, Paul C. (1984): Accord and Discord in Agency-Client Perceptions of Creativity, Journal of Advertising Research, 24 (5): 9-24.

Moorman, Christine and Anne S. Miner (1997): The Impact of Organizational Memory on New Product Performance and Creativity, Journal of Marketing Research, 34 (1): 91-106.

Mumford, Michael D. and Dean K. Simonton (1997): Creativity in the Workplace: People, Problems, and Structures, Journal of Creative Behavior, 31 (1): 1-6.

Myers, Jack (2004): Advertising Accountability, R-o-I \& Sarbanes-Oxley Concerns Spawn Audit Industry, http://www.mediavillage.com/jmr/2004/07/07/jmr-7-7-04/ (Access date: 200801-14).

Naik, Prasad A. and Kalyan Raman (2003): Understanding the Impact of Synergy in Multimedia Communications, Journal of Marketing Research, 40 (4): 375-388.

Newell, Allen, J .C. Shaw, and Herbert A. Simon (1959): The Processes of Creative Thinking, Rand Corporation: Santa Monica, CA.

Nunnally, Jum C. and Ira H. Bernstein (1994): Psychometric Theory, McGraw-Hill: New York.

Nyilasy, Gergely and Leonard N. Reid (2009): Agency Practitioner Theories of How Advertising Works, Journal of Advertising, 38 (3): 81-96.

Ogilvy, David (1963): Confessions of an Advertising Man, Atheneum: New York.

Pieters, Rik, Luk Warlop, and Michel Wedel (2002): Breaking Through the Clutter: Benefits of Advertisement Originality and Familiarity for Brand Attention and Memory, Management Science, 48 (6): 765-781.

Reinartz, Werner, Manfred Krafft, and Wayne D. Hoyer (2004): The Customer Relationship Management Process: Its Measurement and Impact on Performance, Journal of Marketing Research, 41 (3): 293-305.

Ringle, Christian, Sven Wende, and Alexander Will (2005): SmartPLS, http://www.smartpls.de (Access date: 2007-09-15).

Rossiter, John R. (2002): The C-OAR-SE Procedure for Scale Development in Marketing, International Journal of Research in Marketing, 19 (4): 305-335.

Rossiter, John R. (2008): Defining the Necessary Components of Creative, Effective Ads, Journal of Advertising, 37 (4): 139-144.

Runco, Mark A. and Robyn E. Charles (1993): Judgments of Originality and Appropriateness as Predictors of Creativity, Personality and Individual Differences, 15 (5): 537-546.

Ruscio, John, Dean Whitney and Teresa Amabile (1997): How Do Motivation and Task Behaviors Affect Creativity? An Investigation in Three Domains, http://search.ebscohost.com/login.aspx? direct $=$ true $\& \mathrm{db}=\mathrm{buh} \& \mathrm{AN}=9013580 \&$ site $=$ ehost-live (Access date: 2011-11-28). 
Saffert, Peter and Werner Reinartz (2011): Creativity in Advertising and Implications for Product Sales Performance, Proceedings of the 33rd INFORMS Marketing Science Conference, Houston, USA

Sarbanes-Oxley-Act (2002): § 1519. Destruction, Alteration, or Falsification of Records in Federal Investigations and Bankruptcy.

Sasser, Sheila L. and Scott Koslow (2008): Desperately Seeking Advertising Creativity, Journal of Advertising, 37 (4): 5-19.

Sasser, Sheila L., Scott Koslow, and Edward A. Riordan (2007): Creative and Interactive Media Use by Agencies: Engaging an IMC Media Palette for Implementing Advertising Campaigns, Journal of Advertising Research, 47 (3): 237-256.

Sethi, Rajesh, Daniel C. Smith, and C. Whan Park (2001): CrossFunctional Product Development Teams, Creativity, and the Innovativeness of New Consumer Products, Journal of Marketing Research, 38 (1): 73-85.

Smith, Robert E., Scott B. MacKenzie, Xiaojing Yang, Laura M. Buchholz, and William K. Darley (2007): Modeling the Determinants and Effects of Creativity in Advertising, Marketing Science, 26 (6): 819-833.

Song, Michael and Mitzi M. Montoya-Weiss (2001): The Effect of Perceived Technological Uncertainty on Japanese New Product Development, Academy of Management Journal, 44 (1): 61-80.

Sternberg, Robert J. and Todd Lubart (1999): The Concept of Creativity: Prospects and Paradigms, in: Robert J. Sternberg (ed.): Handbook of Creativity, Cambridge University Press: Cambrigde, 3-15.

Stone, Gerald, Donna Besser, and Loran E. Lewis (2000): Recall, Liking, and Creativity in TV Commercials: A New Approach, Journal of Advertising Research, 40 (3): 7-18.

Sullivan, Luke (2003): Hey, Whipple, Squezze This: A Guide to Create Great Ads, Wiley: New York.

Thorndyke, Perry (1977): Cognitive Structures in Comprehension and Memory of Narrative Discourse, Cognitive Psychology, 9 (1): 77-110.
Till, Brian D. and Daniel W. Baack (2005): Recall and Persuasion: Does Creative Advertising Matter?, Journal of Advertising, 34 (3): 47-57.

Van Bruggen, Gerrit H., Gary L. Lilien, and Manish Kacker (2002): Informants in Organizational Marketing Research: Why Use Multiple Informants and How to Aggregate Responses, Journal of Marketing Research, 39 (4): 469-478.

W\&V-Kreativ-Ranking (2009): W\&V Kreativ Ranking, Werben und Verkaufen, 83 (24): 1-4.

Wentz, Laurel (2005): At Cannes, the Lions Say "Grrr", Advertising Age, 76 (26): 1-2.

West, Douglas C. (1993): Cross-National Creative Personalities, Processes, and Agency Philosophies, Journal of Advertising Research, 33 (5): 53-62.

West, Douglas C., Arthur J. Kover, and Albert Caruana (2008): Practitioner and Customer Views of Advertising Creativity, Journal of Advertising, 37 (4): 35-45.

White, Erin (2003): Agencies Face New Accountability, Wall Street Journal, 10 (2): 16.

Young, Charles E. (2000): Creative Differences Between Copywriters and Art Directors, Journal of Advertising Research, 40 (3): $19-26$.

\section{Biographies}

Raoul V. Kübler is a PhD student at the Institute of Innovation Research at the University of Kiel. His main fields of research are advertising, product recall and corporate crisis communication as well as mobile app marketing.

Dennis Proppe holds a $\mathrm{PhD}$ from the Institute of Innovation Research at the University of Kiel. He is the CEO of the G|PREDICTIVE Gradient GmbH in Hamburg, Germany and consults worldwide-leading companies on marketing budget allocation. 